\title{
Evaluating the uses and realizing the benefits of social media use in politics
}

\begin{abstract}
Social media use in politics is evolving to become significantly more complex. The increased use of social media in a political context presents several challenges. Among these are the impact of social media on the control of information, information literacy, and the digital divide. At the same time, the opportunities for sharing, collaboration, and engagement provided by the medium of social media are crucial to understanding how and why these tools can and should be used in politics.
\end{abstract}

\footnotetext{
About the Author(s): Catherine McGoveran (MLIS Candidate, 2013) has a BA Honours in Political Science and French from Carleton University. She has experience with student government and in academic and government libraries, and her recent research has focused on Canadian elections and social media use in politics.
} 


\section{Introduction}

The use of social media in politics is beginning to fundamentally change the way politics and government operate in Canada and around the world. While the use of the internet as an influential campaign tool began in 2004 with Howard Dean's presidential campaign, the 2008 Obama presidential campaign was the one that capitalized on, and demonstrated the potential of online social media, the ways in which it can be used, and the outcomes that can be achieved (Farina et al., 2011; McGrath, 2011). There is, however, a fundamental disparity within the trend of increasing social media use in politics. Within the public sphere specifically, there are distinctions between the use of social media during and outside of elections by politicians and political candidates and the use of social media by government bodies and legislative institutions (Anger \& Kittl, 2011). The former are typically much more consistent and active in their use of social media, whereas the use of social media by the latter is very limited.

A consideration of the evolving ways in which social media tools are used in politics is necessary to examine its impact on the information society, policy development, and public oversight and engagement. To demonstrate the impact of social media use in these ways this paper will examine how social media is used and where, supplemented by specific examples to provide context and perspective on what is possible in the field. The primary analysis of the paper is conducted within the Canadian context. While important advancements in the use of social media in politics are being made around the world, extensive examination of the international context is beyond the scope of this paper. As such, the paper is limited to parliamentary systems that are similar in nature to Canada's for the purpose of providing a comparative context and perspective.

\section{Framework}

There are many types of social media applications that are being used in politics today. Social media, often used interchangeably with the term web 2.0, includes blogs, forums, microblogs, and websites for media sharing and social networking (Auer, 2011; Chun, Shulman, Sandoval, \& Hovy, 2010). This type of technology is related to concepts such as user-generated information and online and public communities (Bateman, Pike, \& Butler, 2011; Bertot, Jaeger, \& Grimes, 2010). The different types of social media and the concepts linked to these technologies are important to keep in mind when trying to understand how, and for what purposes, social media can be used in politics.

In the context of this paper, politics refers to government departments and agencies, legislative institutions, and political actors. Government departments and agencies are the bodies that deliver government services and implement legislation. Legislative institutions are responsible for providing the space within which partisan politics operate. Political actors include elected and appointed officials who debate and carry out legislative initiatives on behalf of the citizens 
they represent. To examine social media in politics, this paper examines its external use by government bodies, legislative institutions, and political actors.

\section{How social media is used}

\section{As a communication tool}

Many, if not all, types of social media applications introduced in this paper are used, be it by parliamentarians, government departments, or elected officials, to disseminate and share information with the public. Communication remains the primary use of social media in politics today, essentially serving as a supplementary information broadcasting tool. A study conducted on the use of Twitter by politicians in Australia highlights that social media continues to be used primarily as a means of sharing information, rather than conversing or engaging with members of the public (Grant, Moon, \& Grant, 2010). As will be discussed, however, this trend is evolving to become more complex, as social media is beginning to be used as an engagement and mobilization tool in the political sphere.

\section{As a facilitator of engagement}

As internet use increases in Canada, with approximately $79 \%$ of Canadians having internet access in 2010 (Statistics Canada, 2010), and around the world, it is becoming increasingly difficult to measure civic engagement by historical standards. Voter turnout, for example, cannot be the sole indicator of how active the public is in regards to politics and everyday issues (Veenhof, Wellman, Quell, \& Hogan, 2008). Engagement of the public goes well beyond the percentage of eligible citizens who cast a vote.

Social media tools have begun to be used in many jurisdictions as a means of fostering public engagement and promoting public oversight. Social media platforms provide users with the opportunity to share opinions, ideas, and ask questions. It is when political institutions and actors make use of this unique platform and its potential for engagement, by actively responding to users and proactively managing the flow of information, that the benefits of engagement can be realized. Benefits of public engagement include receiving low-cost information for the improvement and development of policies and services, while demonstrating a commitment to transparency and public oversight (Bertot et al., 2010).

\section{As an election campaign tool}

The use of social media tools during election campaigns has become an essential element to becoming or remaining competitive. The election period also remains one of the most active times and involves the most active users of social media in politics (Anger \& Kittl, 2011). Social media tools can be used to mobilize and engage citizens for events, rallies, campaigning, and voting, but also to disseminate and encourage the circulation of political information. These two methods are not always used simultaneously. Social media use in politics for the purpose of 
engagement is an emerging trend, whereas its use for the purpose of information dissemination is well established (Clarke, 2010; Hollingworth \& Cooper, 2011).

Used as an election campaign tool, social media also allows like-minded and interested users to become connected across physical boundaries. This is particularly beneficial in countries like Canada, where the population can often be quite dispersed. In the United Kingdom, social media played an influential role in the 2010 election and was described by some as being the country's first "social media election" (New Zealand Parliamentary Library, 2011). The election was further described by the Hansard Society as having effectively used social media to engage citizens, raise the profile of the election and the candidates involved, and become a significant source of information that challenged mainstream media (New Zealand Parliamentary Library, 2011).

As mentioned, the 2008 presidential election in the United States set a precedent for the use of social media applications as election tools. This particular campaign saw a significant increase in voter turnout, particularly of youth who traditionally exhibit low voting levels. Overall turnout reached its highest point since 1960 and youth turnout, for those below 29 years of age, reached the second highest level in history (McGrath, 2011). While the potential correlation between social media use by electoral candidates and voter turnout did not continue to the 2010 election, when turnout again declined, it was nonetheless an important shift that has influenced how election campaigns are constructed and carried out in present day. There has yet to be a presence of candidates who use social media tools to respond to, engage, and mobilize citizens to act and become involved in meaningful ways. Using social media to engage is a trend seen in the United Kingdom and the United States and is beginning to be realized elsewhere.

\section{Where and by whom social media is used}

Social media use in politics does not follow a standard trend, nor is it easy to measure and evaluate. The difficulty of evaluation comes from the fact that there is a significant difference between having a social media presence and having an active social media presence. For example, some politicians may have Facebook pages but are not posting updates frequently, or government departments may have Twitter feeds but are not responding to or engaging users who ask questions through the same medium. It is also difficult to determine what is considered "frequent use." Posting or engaging once a month, week, day, or hour? There is nonetheless an important correlation to be drawn between the provision of information via social media by government bodies, and political actors and institutions and the receiving of this information by the public. The existence of proactive, timely exchanges is a critical 
indicator of active use. While there are some websites and studies that attempt to evaluate social media use, quantitative study in this field remains limited. ${ }^{1}$

\section{Political parties}

Whether it is a political party fan page on Facebook for people to show their support, a Twitter account to keep people informed on party positions and events, or a Flickr account that allows users to view and share photos, political parties are attempting to take advantage of the opportunities provided by having a significant social media presence. Politically slanted, partisan messages by parties are published and shared via numerous social media platforms. Some political parties are more active in their use of social media than others, but its use has undoubtedly become a necessity in partisan politics. This is because there is a significant potential for the politically partisan information shared by parties via social media to be shared or forwarded by other users (Auer, 2011). As noted, this is the case during election periods in particular, though individual candidates are typically more active than party organizations.

All of the five major Canadian federal political parties have a social media presence. Upon review of each of the five parties' websites, it became clear that there are varying degrees to which the parties, as organizations, are involved in and reaching out through social media applications. The ways in which social media tools are highlighted on the websites of political parties, and the mediums which are emphasized provide an indication of the inherent value each party places on social media.

\section{Parliament}

Social media is typically used as a tool by parliaments or legislatures for the purpose of information sharing, rather than multidirectional engagement between information providers and consumers. The dissemination of information is an appropriate use of social media by legislative institutions because these are the institutions within which the development and passage of legislation takes place. While legislative institutions have a significant mandate for engaging with citizens, particularly through legislative committees, further engagement through social media could be an important way of soliciting feedback about the presentation or accessibility of the information provided by this institution.

While there are a significant number of ways for users to share the information provided on the website of the Parliament of Canada, the Parliament itself is not currently using social media as a means of engagement or even active dissemination of information. This is in stark contrast to the work of other comparable institutions, such as the United Kingdom Parliament. The UK Parliament is quite active in its use of social media. There is a Twitter feed, YouTube

1 For more information about social media evaluation please review Politwitter (2011) and Grant, W. J., Moon, B., \& Grant, J. (2010). 
channel, Facebook page, and Flickr account that are updated frequently, allow comments, and provide the opportunity for the public to follow the on-going activities of Parliament. There is even a blog entitled "Lords of the Blog." This blog is supported by the Hansard Society, with a group of about twenty-three active members of the House of Lords authoring posts. While there is a disclaimer that indicates that the views presented on the blog are those of the authors, not of the institution the authors represent, it is a new and innovative way of boosting citizen awareness of and engagement with legislative institutions (Hansard Society, 2011).

\section{Parliamentarians}

Elected and non-elected legislative officials play a significant, often active role in using social media. Parliamentarians, who in the federal Canadian context include both Members of Parliament and Senators, are increasingly embracing various forms of social media. As a group, parliamentarians represent an element of social media use in politics that is consistently more active than others, such as parliament (Anger \& Kittl, 2011). While most political parties have social media accounts for users to follow and retrieve information, it is often the individual elected members and candidates that are the most active and engaged.

Parliamentarians in New Zealand are using social media in increasing numbers. In a report released by the New Zealand Parliamentary Library (2011), it was indicated that the majority of parliamentarians are using social media applications. The same caveat was provided in the report as has been in this paper, that there is an important distinction to be made between the usage and active usage of social media. Data can be provided on the number of parliamentarians who have social media accounts, but it is more difficult to extrapolate data on how actively, and in what ways, accounts are being used (New Zealand Parliamentary Library, 2011).

\section{Government departments and agencies}

Governments are using social media as communication and engagement tools, sharing information with the public and, in some instances, soliciting feedback. Policies are being developed by various levels of government, as the benefits of social media use in this context are beginning to be realized. Policy development in this area is important as governments use social media in different ways than political institutions and actors. Where political actors may use social media for the purposes of input on the development of legislation, sharing partisan positions on issues, and carrying out parliamentary duties, governments may use social media for the purposes of implementing legislative decisions and providing services and information to the public.

Social media use in politics in Canada is undergoing a number ofimportant developments, as it is beginning to see an increasingly broad application and more complex use. The introduction of an official, federal social media policy is one such development. The Guideline for External Use of Web 2.0, released on 18 November 2011, is an important step forward for the 
Canadian government in that it begins to provide parameters around which departments and civil servants can operate (Treasury Board of Canada Secretariat, 2011). The social media landscape within the context of the federal government was previously very ambiguous, with employees having no clear, official direction as to what is and is not an appropriate use of social media. The guideline is also beneficial in that it encourages, in writing, the use of web 2.0 tools by government departments and civil servants (Eaves, 2010).

At the same time, however, while the guideline may encourage the use of social media by departments and employees, the reality that many social media sites are blocked and inaccessible by employees in their offices highlights the difference between encouragement and mandated requirement (Eaves, 2010). It also limits the likelihood that departments that are not currently using social media will be encouraged to begin using these tools. If social media is not an integrated, mandated part of government websites, activities, and policies, trust will not be fostered. Without trust, it is unlikely that the benefits of social media use can be realized (Anger \& Kittl, 2011).

The dilemma between encouraged use and mandated use is well described by June, Hong, and Sung-Min (2011, p. 129), who state that "governments that want to understand the implications of social media must move beyond simply reacting to social media by incorporating and internalizing it as part of its basic processes." This approach can and should be extended to all political and governmental use of social media. The provision of official guidelines is an important development and step towards the necessary integration highlighted by June et al., and it brings the federal government more in line with the social media practices of other federal jurisdictions.

Some Canadian provinces have made significant strides in the development of social media policies. In September 2010, British Columbia published guidelines for the use of social media by government employees in a document titled Policy Summary No. 33: Use of Social Media in the B.C. Public Service. While there were, and may still be, concerns from the public about the personal use of social media applications while at work, the B.C. government is emphasizing that its use of social media is a means of interacting and engaging with the public for the improvement of government services (British Columbia, 2010; British Columbia Ministry of Labour, 2011). The policy document itself is also very encouraging in illustrating how policies can be developed effectively. The document is two pages, uses clear and plain language, and references external material where necessary.

\section{Issues and challenges}

The challenges inherent to social media use in politics result from the multidimensional nature of the medium. Social media goes beyond stationary, static websites to interactive tools that provide the opportunity for immediate response and interaction. The nature of social media thus makes it difficult for use in politics because of the difficulty it poses for the control and 
consistency of information (Farina, 2011). Political users of social media are faced with the challenge of being both proactive and reactive, which can leave significant room for error, misinformation, and a lack of government control (Farina, 2011). Any information, including that which is inaccurate or negative, can spread virally through social media, leading many political users to exercise significant caution (June et al., 2011). The issue of the control of information also relates to the long-term preservation of information. If social media is to be used to engage in policy development and oversight, attention must be given to how the information and knowledge created will be preserved over time (Jaeger \& Bertot, 2010). It is for these reasons that policies should be developed to detail the ways in which governments and the public service can and should use social media, the responsibilities inherent, and the objectives that should be strived for. Expectations must be managed and so too must attention be paid to the contexts and audiences within and with which individuals are interacting (Hollingworth \& Cooper, 2011).

There are also external challenges with which social media use in politics must contend. The digital divide and information literacy are examples of such external challenges that must be considered when examining social media use in politics. The digital divide, experienced by users who do not have the skills, resources, or knowledge necessary to access or use digital technology, reflects the reality that social media use in politics must be coupled with other information dissemination and engagement strategies (Bertot et al., 2010). It cannot be assumed that all Canadians have access to these technological applications, but it also cannot be overlooked that individuals may face other or additional barriers as a result of information illiteracy. Not all people know how to locate, evaluate, and analyze information in meaningful ways. At the same time, however, social media provides the opportunity for political users to reach a specific segment of the population that may not otherwise be accessed. This segment includes youth and the growing number of digitally savvy citizens (Anger \& Kittl, 2011). When coupled with more traditional forms of communication, including general internet use, service centres, phone lines, print material, and traditional media, social media use can be an effective means of promoting transparency, increasing access to government information, and engaging the public.

Information poverty is another issue social media interacts with and may be able to address, at least in part. Information poverty can occur when individuals or groups lack the skills or means necessary to access, interpret, and apply information, when there is an inadequate availability of essential information, or when information is poorly managed (Britz, 2004). The collaborative nature of social media, for example, can contribute to the capacity for resource discovery, in turn, working to reduce the prevalence of information poverty (Kesselman, 2010). In the United Kingdom, social media is being used by Parliament as one of several means of addressing the issue of information poverty. The UK has stated that its use of social media has been "to promote public understanding of the work and role of Parliament through the provision of information and access, by informing, promoting, and listening and reaching out to people and 
communities that wouldn't be visiting the Parliament website" (Houses of Parliament, 2010). This is an interesting example of the possibilities of social media use in politics and how parliaments can disseminate information, engage the public, and seek to address information poverty in new ways. In an evaluation of digital media use and potential use in Parliament, conducted by the Hansard Society, it was found that social media can and should be used as one of several means of increasing access to information about parliament (Williamson \& Fallon, 2011).

\section{Impacts and opportunities}

The benefits of social media use in politics are, despite the challenges, beginning to be realized and demonstrable. Social media provides an opportunity for the quick, low cost dissemination of information and solicitation of feedback (June et al., 2011). The opportunity to engage citizens is real and can impact transparency and policy development (June et al., 2011). It is not, however, the existence of the opportunities that social media provides that should be questioned, but rather whether the opportunities are being adequately capitalized upon by the actors and institutions in question. The examples provided throughout this paper demonstrate that social media has yet to have a significant, positive impact on the information society, policy development, and public oversight and engagement.

\section{The information society}

The impact of social media use in politics is related to its effect on the information society. Social media provides the opportunity not only for the distribution of information, but also the exchange and creation of information. The collaborative nature of social media fosters the sharing of ideas and the creation of thematic communities of discussion, which can benefit public understanding and knowledge (Papaloi \& Gouscos, 2011). At the same time, however, it should be realized that the use of social media in politics results in an indirect cost to the public. Given that the taxpayers are those that fund much of the institutions of government and politics, social media use in this sphere comes at a cost because of the investments required for policy development, training, and active use of the applications. There is a significant commitment of time and resources for the integration of social media into the structures of government and for the effective, active use of these tools (Anger \& Kittl, 2011). The actual costs of social media use in politics cannot be easily quantified, nor is it straightforward. This makes cost-benefit analysis difficult, but does not significantly take away from the trends towards social media use or the public desire for transparency and engagement.

\section{Policy development and public oversight and engagement}

The presentation of contextual information throughout this paper has made clear that there is significant potential for social media to impact policy development and public oversight in positive ways. One side of the debate emphasizes that social media fosters public oversight by 
providing a platform for public engagement, and government accountability and transparency (Grant et al., 2010). The other side of the debate argues that social media is limited in its capacity to make a positive impact on policy development and public oversight, because it is time consuming and may not be fully representative or accessible (Clarke, 2010). In relation to engagement, the impact of social media has been questioned by some for its potential to lead to "cyberpolarization," and has been labelled by others as "slacktivism" (Christensen, 2011; Grant et al., 2010). Such characterizations are, however, very broad and cannot be accurately applied to the whole of social media use in politics, particularly not social media use by governments and political institutions and actors. In fact, it is has been demonstrated that social media users are not just consumers of information, but are increasingly creating information and contributing to knowledge production through online social media (Bateman et al., 2011).

As the habits and activities of the public change towards an increased use of digital and mobile technologies, so too must political users adapt. The public is increasingly demanding that governments and political actors engage and become more transparent (Hollingworth \& Cooper, 2011). These trends should be capitalized upon by government bodies and political users, for the purposes of harnessing the public's willingness and desire to contribute to the information society in this way, and for the trend's potential impact on policy development.

To this end, social media makes available opportunities for barriers to participation to be broken down. Such barriers could include a lack of political or institutional literacy and a lack of knowledge about policy development and how it affects the everyday lives of citizens (Farina, 2011). The active use of social media by governments, legislative institutions, and political actors broadens the access points through which information can be obtained. Participation can be facilitated and fostered with increased access to information (Christensen, 2011). It goes back to the argument of - and differentiation between - the use and active use of social media in politics. In this context, the onus is on governmental and political user groups, rather than the public, to take advantage of the opportunities provided by social media for the impact of public engagement to been seen.

Political users must be willing to actively engage with broad audiences, not only broadcasting information but also responding to questions and soliciting feedback where possible. Using social media in this way provides the public with a new platform to access government and political information and to connect with political users. It also gives the public opportunities for providing constructive feedback, sharing ideas, and asking questions of those who are accountable to taxpayers (Papaloi \& Gouscos, 2011). The use of social media in active, engaging ways demonstrates a desire on the part of the government, legislative institution, or political actor to become more transparent and accountable (Papaloi \& Gouscos, 2011). 


\section{Concluding remarks}

Social media is continually developing and evolving to have new uses and applications. Within this evolution, there is an important distinction to be made between the use and active use of social media. While the use of social media in politics is difficult to measure, examples from Canada and other countries demonstrate the inherent challenges and opportunities. There are significant challenges to be overcome, such as those relating to the control of information, the digital divide, and information literacy. At the same time, social media use in politics provides an opportunity to contribute to efforts to reduce information poverty.

The opportunities for sharing, collaboration, and engagement provided by the medium of social media are crucial to understanding how and for what reasons these tools can and should be used in politics. While social media can undoubtedly make demonstrable impacts, it requires active, timely, and mandated engagement. What is most important for the future of this field is that social media use by governments, legislative institutions, and political actors continues to move forward from the traditional broadcasting of information towards the emerging trend of sharing, collaborating, and engaging for the benefit of the information society, policy development, and public oversight and engagement. 


\section{References}

Anger, I., \& Kittl, C. (2011). Social media in European Governmental Communication. Proceedings Of The European Conference On E-Government, 43-52.

Auer, M. R. (2011). The policy sciences of social media. Policy Studies Journal, 39(4), 709736. http://dx.doi.org/10.1111/j.1541-0072.2011.00428.x

Bateman, P. J., Pike, J. C., \& Butler, B. S. (2011). To disclose or not: Publicness in social networking sites. Information Technology \& People, 24(1), 78-100.

Bertot, J. C., Jaeger, P. T., \& Grimes, J. M. (2010). Using ICTs to create a culture of transparency: E-government and social media as openness and anti-corruption tools for societies. Government Information Quarterly, 27(3), 264-271. http://dx.doi.org/10.1016/j.giq.2010.03.001

Bloc Quebecois. (2011). Nouvelles. Retrieved 11/29/2011, from http://www.blocquebecois.org/accueil.aspx

British Columbia. (2010). Policy Summary No. 33: Use of Social Media in the B.C. Public Service. Retrieved 12/04/2011, from http://www.cio.gov.bc.ca/local/cio/informationsecurity/policy/summaries/33 social medi a.pdf

British Columbia Ministry of Labour, Citizens' Services and Open Data. (2011). Citizen engagement. Retrieved 11/28/2011, from http://www.gov.bc.ca/citz/citizens engagement/index.html

Britz, J. J. (2004). To know or not to know: A moral reflection on information poverty. Journal of Information Science, 30(3), 192-204. http://dx.doi.org/10.1177/016555150404466

Christensen, H. S. (2011). Political activities on the Internet: Slacktivism or political participation by other means? First Monday, 16(2). Retrieved from http:// www.firstmonday.org/htbin/cgiwrap/bin/ojs/index.php/fm/article/view/3336/2767

Chun, S. A., Shulman, S., Sandoval, R., \& Hovy, E. (2010). Government 2.0: Making connections between citizens, data and government. Information Polity: The International Journal of Government \& Democracy In The Information Age, 15(1/2), 1-9. http://dx.doi.org/10.3233/IP-2010-0205 
Clarke, A. (2010). Social media 4: Political uses and implications for representative democracy. Retrieved 11/28/2011, from http://www.parl.gc.ca/Content/LOP/ResearchPublications/2010-10-e.htm

Conservative Party of Canada. (2011). Conservative Party of Canada. Retrieved 11/29/2011, from http://www.conservative.ca/home/

Eaves, D. (2011). The Canadian Government's new Web 2.0 guidelines: The good, the bad, and the ugly. Retrieved 12/04/2011, from

http://eaves.ca/2011/11/23/the-canadian-government-new-web-2-0-guidelines-the-goodthe-bad-the-ugly/

Farina, C., Miller, P., Newhart, M. J., Cardie, C., Cosley, D., \& Vernon, R. (2011).

Rulemaking in 140 characters or less: Social networking and public participation in rulemaking. Pace Law Review, 31(1), 382-463.

Grant, W. J., Moon, B., \& Grant, J. (2010). Digital dialogue? Australian politicians' use of the social network tool Twitter. Australian Journal of Political Science, 45(4), 579-604. http://dx.doi.org/10.1080/10361146.2010.517176

Green Party of Canada. (2011). Green Party of Canada. Retrieved 11/29/2011, from http://greenparty.ca/

Hansard Society. (2011). Lords of the blog. Retrieved 11/29/2011, from http://lordsoftheblog.net/

Hollingworth, A., \& Cooper, T. (2011). Why government must do better with Web 2.0. Public Manager, 40(3), 30-34.

Houses of Parliament. (2010). Parliament labs: Social media stats update. Retrieved 12/02/2011, from http://parliamentlabs.wordpress.com/2010/01/21/social-media-stats-update/

Jaeger, P. T., \& Bertot, J. (2010). Transparency and technological change: Ensuring equal and sustained public access to government information. Government Information Quarterly, 27(4), 371-376.

http://dx.doi.org/10.1016/i.giq.2010.05.003

June, P., Hong, C., \& Sung-Min, P. (2011). Social media's impact on policy making. SERI Quarterly, 4(4), 125-129.

Kesselman, M. (2010). Redefining the value of information: Exploring the new equation. Library Hi Tech News, 27(3), 4-6. 
Liberal Party of Canada. (2011). Liberal Party of Canada. Retrieved 11/29/2011, from http://www.liberal.ca/

McGrath, M. (2011). Technology, media, and political participation. National Civic Review, 100(3), 41-44.

http://dx.doi.org/10.1002/ncr.20075

New Democratic Party of Canada. (2011). Canada's New Democrats. Retrieved 11/29/2011, from

http://www.ndp.ca/

New Zealand Parliamentary Library. (2011). New Zealand Parliamentarians and online social media. Retrieved 12/02/2011, from http://www.parliament.nz/en-NZ/ParlSupport/ResearchPapers/e/8/8/00PLSocRP11021New-Zealand-Parliamentarians-and-online-social-media.htm

Papaloi, A., \& Gouscos, D. (2011). E-Parliaments and novel parliament-to-citizen services. EJournal of Democracy and Open Government, 3(1), 80-98.

Parliament of Canada. (2011). Parliament of Canada. Retrieved 12/02/2011, from http://www.parl.gc.ca/Default.aspx?Language=E

Politwitter. (2011). Canadian political tweets. Retrieved 12/02/2011, from http://www.politwitter.ca

Statistics Canada. (2010). The daily: Canadian internet use survey. Retrieved 12/02/2011, from http://www.statcan.gc.ca/daily-quotidien/110525/dq110525b-eng.htm

Treasury Board of Canada Secretariat. (2011). Guideline for external use of Web 2.0. Retrieved 11/29/2011, from http://www.tbs-sct.gc.ca/pol/doc-eng.aspx?id=24835\&section=text

United Kingdom Parliament. (2011). UK Parliament. Retrieved 12/02/2011, from http://www.parliament.uk/

Veenhof, B., Wellman, B., Quell, C., \& Hogan, B. (2008). How Canadians' use of the internet affects social life and civic participation. Retrieved 12/01/2011, from http://www.statcan.gc.ca/pub/56f0004m/56f0004m2008016-eng.pdf

Williamson, A, \& Fallon, F. (2011). Transforming the future parliament through the effective use of digital media. Parliamentary Affairs, 64(4), 781-792. http://dx.doi.org/10.1093/pa/gsr028 